\title{
Empirical Performance Chart for Ground Support in Seismic Conditions at Mt Charlotte
}

\author{
P.A. Mikula Mikula Geotechnics Pty Ltd, Australia \\ M.F. Lee AMC Consultants Pty Ltd, Australia
}

\begin{abstract}
Methods of estimating dynamic-capable ground support requirements from first principles are limited by the complexities of seismic event mechanisms, the susceptibility of excavations to damage and the behaviour of ground support systems. Some of these complexities were bypassed at the Mt Charlotte gold mine by adopting an alternative site-specific empirical approach, based on underground observations of seismic damage and the performance of ground support.
\end{abstract}

Relationships were derived between peak particle velocity due to seismicity, the energy absorption capacity of ground support systems, and the damage occurring in excavations. A ground support design chart was developed for dynamic situations to enable estimation of the minimum required energy absorption capacity for ground support. Alternatively, given a particular seismic event magnitude and location, the chart can be used to indicate likely ground support performance in dynamic situations, in terms of the expected damage to ground support.

The chart has been successfully applied to assess dynamic ground support requirements in development used to mine remnants in the seismically active ROB5 stoping block. A key advantage of this empirical approach is that it is calibrated to the peculiarities of the specific mine site.

\section{Introduction}

Most mining company policies dictate a "no harm" approach to mining. To provide a safe working environment in mines prone to seismicity, part of the strategy is the provision of adequate ground support for all situations and for the life of the mine. But to achieve this, these mines must demonstrate or establish the adequacy of their ground support under dynamic loading conditions. Unlike static loadings, dynamic situations introduce complexities and uncertainties into the engineering calculation of support requirements. Dynamic ground support designs are therefore often conservative, but occasionally failures still occur.

It is not a trivial exercise to confidently specify dynamic-capable ground support requirements. The principles involved are still only poorly understood and there is uncertainty as to how to approach an engineering design, especially using mechanics from first-principles. Practitioners need to consider at least the following: seismic event mechanisms, the susceptibility of the excavation to damage and the dynamic characteristics of various support and reinforcement elements. Most methods are based around the predicted peak particle velocity (PPV) of a credible event and the energy capacity of support - Kaiser et al. (1995); Heal (2005); Albrecht and Sharrock (2006); Li (2002). While this is simplistic, it is at least a starting point.

It is an attractive option to bypass some of the above engineering complexities in favour of an empirical observation-based design chart. This paper describes an empirical methodology developed for the Mt Charlotte gold mine, Kalgoorlie, Western Australia. The aim was to provide a rational design chart for dynamic-capable ground support, for seismic prone situations at Mt Charlotte. It is based on underground observations, seismic damage and the performance of support, but unfortunately it was not possible to avoid relying on PPV estimates from event magnitude data.

Background information on geological, geotechnical and production aspects of the Mt Charlotte mine have previously been documented in Mikula and Lee (2000). 


\section{Complexity of dynamic conditions}

As background and context for the empirical design approach, some of the complex nature of dynamic conditions in mines is summarised below.

\subsection{Seismic event mechanisms}

Several failure mechanisms can produce seismic events in underground mines (Ortlepp, 1997). While one of the mechanisms might be responsible for initiating a seismic event, several of them are often evident when an associated fall of ground (rockburst) is investigated. Also, the initiating mechanism may not be the main contributor to the energy released or the damage. Mechanisms include:

Shearing on pre-existing structures or contacts (fault, shears, dykes, etc.): For significant irrecoverable displacement at failure, shearing on the structures must be mechanically satisfied and physically possible. The quantity, rate and frequency of the radiated energy (i.e. the seismic event) is a function of the following: stiffness and stored strain (elastic) energy of the loading system; strength and deformation characteristics of the structure (scale dependent); the total displacement; and how quickly it occurs.

The inherent roughness of structures and the progressive interlock of blocks mean that shearing is not a selfpropagating failure mechanism. Shearing tends to be a process of slip then stick, which may occur repeatedly during a single episode of failure.

Compressive failure of intact rock due to high stresses: This usually involves crushing and the development of shear planes on all scales, ranging from breakout or slabbing around openings to the failure of large "structured" pillars. The main issues are typically rock strength versus rock stress, but strength is scale dependent. The size of associated seismic events is largely a function of the stiffness and stored strain energy of the loading system, versus the rate and amount of closure.

Strain bursting, or the violent slabbing of exposures, is a special case. It is related to the development of extension (tensile) fractures, rather than compressive shear failure through intact rock. Rocks prone to strain bursting typically have high stored strain energy, low energy consumption during cracking and numerous microcracks available for crack nucleation (i.e. failure).

Tensile failure or violent buckling of the rock mass: This seismic event mechanism is most common in situations where openings are parallel to bedding or laminations (e.g. buckling and floor heave in coal mines, but also in some metalliferous mines). The rapid development of large slabs is also possible in massive rocks due to locally excessive tensile stresses, similar to the exfoliation of granite outcrops.

The above failure mechanisms only initiate after a perturbation in the local stress field. Internal and external sources that control the far-field stresses include mining (the most common and easily understood source); tectonics (periodic or irregular fluctuations in crust loads, due to shearing on faults, with or without earthquakes); plate collisions and deep-seated mantle movements; and extraterrestrial (tidal effects of the moon and sun).

\subsection{Excavation susceptibility to damage}

Several factors can affect the proneness of openings to seismic damage. As different factors can act collectively, it is often very difficult to confidently determine which factor was the controlling influence at any particular site.

Event energy: The incident dynamic wave energy from an event is related to the square of the PPV. But it is difficult to determine PPV, whether average or largest expected, at the excavation. PPV is characterised as either "near-field" (within twice the source radius of the source) where it not well understood, or "far-field" (at larger distances from the source) where PPV can be better estimated using far-field scaling laws (Heal, 2005).

Blocky rock: Joints are energy sinks and ground support (screen plus bolts) assist the process.

Joints slide, grind and absorb incoming dynamic wave energy, perhaps sufficiently in numerous cases to maintain the excavation stability. Sliding is an inherently stable motion; movement stops when the external 
force drops below the shear strength. In sufficiently blocky rock (say, Q'<20) it also seems that dynamic amplitude and frequency are favourably modified to reduce dynamic wave reflection at the excavation surface, thereby reducing the chance of ejection.

Untensioned bolts effectively increase joint confinement, thereby mobilising joint cohesion. Tensioned bolts also increase the normal load on joints, which mobilises higher joint strength prior to shearing. Bolts essentially dictate that energy must be expended by shearing on joints before a large displacement (ejection) is possible. Screen (mesh or fibrecrete) actively resists bulking and ejection between bolts.

Presence of structure: Seismic damage and ejection is common adjacent to exposed structures (faults, shears and continuous joints), especially where the angle, between the structure and the excavation, is $<60^{\circ}$.

Neglect of wall support: During a dynamic event, the effect of gravity is often overwhelmed. Unbolted walls can be more damaged than backs. Floors heave can also occur, but often broken rock fill on the floor limits damage and ejection.

It is interesting that at Mt Charlotte, rock ejection has only been observed in shoulders and walls. Reasons for this might include:

- Backs are invariably better supported.

- It is more difficult to determine whether rock has fallen or been ejected from backs.

- Walls stresses are often low, maybe tensile, and the rock mass is therefore more easily loosened by incoming dynamic energy (e.g. from blasting or seismic events).

Surface support (screen): It is common experience that screen (mesh or fibrecrete) can significantly reduce seismic damage, and therefore reduce the seismic hazard. Appropriate surface support is essential, so that failure does not occur around bolt collars, and to provide good anchorage for bolt collars. Interestingly, a Swedish numerical study of fibrecrete thickness and blast vibration showed that thinner fibrecrete was more resilient than thicker fibrecrete (Ansell, 2004); momentum being the driving factor.

Opening resonant frequency: It is commonly observed that boreholes are too small and open stopes are too large to be affected by dynamic events, yet typical 5 by $5 \mathrm{~m}$ development can experience significant damage from a nearby seismic event. Why?

Perhaps the proneness of an opening to damage is related to the incoming frequency spectrum of the seismic wave versus the frequency response of the opening. For example, for ground motion generated by a seismic event propagating through rock with S-wave velocity around $3600 \mathrm{~m} / \mathrm{s}$ and a dominant frequency of the dynamic wave of $200 \mathrm{~Hz}$, the wavelength would be $18 \mathrm{~m}$ (plus harmonics), which is in the order of the dimensions of mine development. These issues are critical to the design of surface buildings and structures so that they are not prone to earthquake damage (Wilson and Lam, 2006).

This aspect of the seismic damage of underground openings requires urgent detailed investigation. Simple modifications to the size and shape (i.e. stiffness - see below) of openings (e.g. wider or "top-hatted") may change their resonant frequency and hence avoid damage.

Local stiffness contrast around openings: Incoming dynamic waves are observed to be amplified in the fractured zone around an excavation, thereby increasing the damage. This is known as the "site effect". This effect is poorly understood, but amplification of the ground motion (the PPV) by a factor of up to 10 times is considered possible. It varies strongly from site to site, possibly depending on the stiffness (thickness, softness, blockiness, etc) and contrast of the fractured zone, compared to the deeper solid rock. In typical Western Australian mines, where fracture zones are generally $<1 \mathrm{~m}$ thick, a quantitative value for the site effect is more likely to be 2 or less (Heal, 2005).

The earthquake analogy is the more violent shaking of buildings founded on thin, well-defined layers of softer rocks (e.g. lake sediments) above stiffer rocks. The stiffness (thickness and modulus) and contrast with the deep rocks are both important. This is another avenue for further investigation. This concept suggests that exposures should be suitably blocky, and have no sharp stiffness contrasts close to the opening. 
Fractured zone thickness: The fractured zone thickness (or failure thickness), as well as being a site of increased PPV as described above, also defines the potential mass of (ejected) rock that might load the support system, and thus the intensity of the damage. It also implies a minimum length of support or reinforcement elements to ensure anchorage in solid ground. Failure thickness depends on at least the presence of geological structure, the rock mass quality, stress-induced fracturing and blast damage.

Proximate faults and contacts: Faults and contacts can act as "wave guides" and focus incoming dynamic energy onto particular areas. Damage is often concentrated on one side of a fault or contact.

Rock properties: Some rock types are more prone to damage. Typically they are "brittle" and massive (e.g. Q' > 60). Common "brittle” Western Australian rocks include buck quartz, carbonated basalts and dolerites, siliceous felsic volcanics, some porphyries and massive sulphides. Under the right conditions, these rocks are also prone to strain bursting (Fraser et al., 2006).

\subsection{Ground support requirements}

There are two basic modes of ground failure: static, which includes a consideration of structure-defined wedges and unravelling of loose blocky or slabby ground; and dynamic, which includes a consideration of impact duration, velocity, acceleration and momentum. Ground support must be able to manage potential failures due to both modes. Firstly, adequate screen must be provided. Then the main concerns are often demand versus support capacity and displacement, but cantilever loadings must be avoided by using appropriate bolt lengths and arrays. In dynamic situations, the motion of the broken rock mass must also be halted before the displacement capacity of any element is reached.

Ongoing quality assurance is necessary to ensure that correct installation and the design capacity of ground support is achieved. Corrosion must be anticipated, as well as the cumulative effect of multiple seismic events. It may therefore be appropriate to apply high safety factors, based on experience, to account for these shortfalls.

All support elements have strengths and weaknesses for given situations. There is not a single screen or bolt type that will be appropriate for all occasions. To provide adequate ground support, it is therefore advisable to install a limited, but well-considered, mixture of support elements.

\section{Study philosophy}

Given the above complexities and uncertainties regarding dynamic conditions, an empirical approach to designing appropriate site-based ground support is attractive; based on observations of seismic damage and the previous performance of ground support.

The investigations reported below relate to Mt Charlotte. A reality check was necessary for support installed in an active mining area considered to be prone to seismicity. The study focused on the back analysis of situations where the installed support was or was not "adequate", for one reason or another, in previous welldocumented instances of seismic damage at the mine.

Mt Charlotte's good documentation of prior seismicity and damage made this work possible. An additional helpful factor is the relatively uniform rock type and quality throughout most of the mine, so these factors should not obscure other data trends. Q' values are typically over 25 in most of the Mt Charlotte dolerite implying a rock mass prone to seismic damage at sufficient stress levels.

Another Western Australian mine, in heavy strain bursting conditions, addressed the question of adequacy of their dynamic-capable support by using a support capacity "multiplier" of 5 to 6 times greater than static computation suggests. The concept of a "Rockburst Support Multiplier" may have merit, and one of the outcomes of the present study was the identification of a rule-of-thumb that is of this nature.

Three sources of data were available for the study, namely seismic parameters, installed support and observed support damage. The ideal study result would be a definitive relationship between the three, but unfortunately these items are not always easily or consistently defined or measured because: 
- The seismic system may not always compute an accurate magnitude, and magnitudes taken alone are not the best measure of the size of an event. Magnitude comparisons can only be general due to varying event types, excavation geometries, rock types, structures and depths.

- Installed ground support may be affected by poor quality control or corrosion, and there can be incorrect recording of the installation.

- Damage records may be based on brief or distant observation, and may not accurately reflect the true level of damage. Determining a cause of the damage is also subjective.

- Inconsistencies are also possible due to data collection by different personnel over the years.

- The mine seismic monitoring system was upgraded in 2004, leading to a discontinuity in monitored data at that time.

Considerable scatter was therefore expected, and found, in relationships.

A key advantage of this kind of parametric study is that it is calibrated to the peculiarities of this mine site. It does not matter greatly if the seismic system has a bias in calculating magnitude, so long as the bias is consistent in both the data collection and the forecasting exercises. Likewise, the energy absorption capacity of a certain bolt type may be an estimate, but as long as that estimate is used consistently a valid forecasting technique can be created.

\section{Scope and method}

The observational and seismic monitoring records held by Mt Charlotte for 36 comparatively large seismic events were examined. They occurred between 28/01/1995 and 4/06/2007 and had a Richter magnitude $\left(M_{R}\right)$ range of 0.7 to 3.5 .

The study method comprised the following:

- Review of the records of Mt Charlotte’s large seismic events and associated damage.

- Compilation of a spreadsheet of relevant seismic data.

- Identification of the ground support installed at each damage site.

- Estimation of the energy absorption capacity of the ground support.

- Estimation of the distance from the damage site to the corresponding event hypocentre.

- Estimation of the PPV at the support location due to the seismic event.

- Charting of PPV, damage, and energy absorption capacity of the ground support.

This approach bypassed the need to specifically consider the plethora of individual factors, as they are automatically canvassed. The observed damage represents a synthesis of all of these factors.

\section{Damage data}

For many of the events, there were multiple damage locations on several levels of the mine, and multiple ground support bolt types and patterns. The study identified 186 separate data sets, each combining seismic, damage and ground support parameters. Damage located in the backs, shoulders and walls was identified separately.

The support damage categories adopted for the project are shown in Table 1 . They were based on those suggested by Kaiser et al. (1992) and Heal et al. (2006), and categories S4 and S5 were combined for the chart presented later in this paper.

\section{Seismic data}

Seismic event parameters provided by the monitoring system included magnitude, location, and $\mathrm{RV}_{\max }$ where $\mathrm{V}_{\max }$ is the PPV at any point and $\mathrm{R}$ is the distance from the event hypocentre to that point. 
Table 1 Adopted ground support damage categories

\begin{tabular}{cl}
\hline Category & Description \\
\hline S0 & No damage. \\
S1 & First signs of distress - rock spall between bolts. \\
S2 & Bolts loaded, plates deformed, mesh bagged but competent, shotcrete cracked. \\
S3 & $\begin{array}{l}\text { Support heavy loaded, few broken bolts, mesh tightly bagged, some mesh torn } \\
\text { or open. }\end{array}$ \\
S4 & $\begin{array}{l}\text { Major damage, many broken bolts, mesh failed, significant rock ejected or } \\
\text { fallen. }\end{array}$ \\
S5 & Complete failure of support components. \\
\hline
\end{tabular}

The $\mathrm{RV}_{\max }$ data was not used for this study. This information came from both the older PSS seismic system and the current ISS, and the two datasets are not directly comparable. The reliability of the PSS recordings of $\mathrm{RV}_{\max }$ value was uncertain, as the values were considerably lower than might be expected.

Instead, far-field PPV was estimated using Equation (1), after Kaiser et al. (1995). Sample values are given in Table 2.

$$
\mathrm{PPV}=\left[1.4 \times 10^{\left(0.5 \mathrm{M}_{\mathrm{R}}\right)}\right] / \mathrm{D}
$$

Where:
$\mathrm{M}_{\mathrm{R}} \quad=\quad$ Richter magnitude of the seismic event.
PPV = Estimated peak particle velocity at the location of interest $(\mathrm{m} / \mathrm{s})$.
$\mathrm{D}=\quad$ Distance from the seismic event to the location of interest (m).

It is acknowledged that while magnitude was used in this study, it is not always a good measure of the size of an event.

Table 2 Estimated PPV (m/s) for combinations of magnitude and distance

\begin{tabular}{ccccc}
\hline Distance (m) & Richter 1.5 & Richter 2.0 & Richter 2.5 & Richter 3.0 \\
\hline 20 & 0.39 & 0.70 & 1.24 & 2.21 \\
60 & 0.13 & 0.23 & 0.41 & 0.74 \\
100 & 0.08 & 0.14 & 0.25 & 0.44 \\
\hline
\end{tabular}

\section{Ground support data}

The installed ground support varied greatly:

- Bolt types:

o Point anchored bolts - resin gewibar, mechanical shell anchor.

o Friction bolts - typically $2.4 \mathrm{~m}$ and $3 \mathrm{~m}$ galvanised jumbo bolts ( $47 \mathrm{~mm}$ diameter).

o Full column resin/cement bolts - cable bolts, grouted friction bolts.

- Pattern - expressed in terms of bolt density; ranged from 0 to 1.23 bolts $/ \mathrm{m}^{2}$.

- Surface support - W-straps were most common. Other surface support included mesh, butterfly plates, shotcrete and thin steel straps that were used with the shell anchors. Shotcrete was very rarely used. 


\section{Support capacity}

Under dynamic loading, the support system must be able to achieve a very onerous specification:

- It must absorb all the incoming dynamic energy.

- It must withstand the associated displacement, no matter how fast.

- The rock between the bolt collars, often broken, must be retained by the surface support in order to minimise overbreak and ensure that the bolts can still function.

- The bolts must still be able to support and retain the static load of the resultant blocky or loosened rock mass.

The energy absorption capacity of a bolt is a function of the area under the load-displacement curve of the bolt. The form of this curve depends on the rate of loading, and may be different for static and dynamic conditions.

Typical static load-displacement curves are available from bolt suppliers, but dynamic curves are still the subject of research. Although admittedly imperfect, static curves were adopted for this study as they were thought unlikely to compromise the empirical nature of the final outcome. Energy absorption capacities were therefore estimated based on data and discussions by Kaiser et al. (1996), and Heal (2005).

Table 3 shows the values used for this study. Zero energy absorption capacity was assumed for Mt Charlotte's mechanical shell bolts because they are typically corroded. Likewise, fibrecrete was set to zero; where it was present it was sprayed over W-straps, without mesh.

\section{Table 3 Energy absorption adopted per support element}

\begin{tabular}{lc}
\hline Support elements & kJ/element \\
\hline 2.4 m cone bolt & 17.5 \\
2.4 m or 3 m jumbo friction bolt (47 mm diametre) & 11 \\
cable bulbed single & 4 \\
cable bulbed twin & 8 \\
$50 \%$ 2.4 m resin rebar / 50\% 3 m friction bolt & 6.75 \\
2.4 m resin rebar (point anchor) (20 mm diametre) & 2.5 \\
2.4 m mechanical shell anchor(15 mm diametre) & 0 \\
fibrecrete, sprayed over bolts, no mesh & 0 \\
\hline
\end{tabular}

\section{Dynamic ground support design chart}

For each damage location (backs, shoulders and walls), estimated PPV was plotted against the calculated energy absorption of the ground support, versus the damage and support performance. Good data was available for development backs, but unfortunately there were too few data points for the shoulders and walls to plot separately. The shoulder, back and wall data was quite similar, so a combined dataset was used to develop the chart (Figure 1). Each charted point represents a damage level as shown in the legend.

Figure 1 also shows the addition of subjectively-placed dashed lines that interpret ground support performance. These lines were based on observation only, and are to be taken as notional, not definitive. Due to the uncertainties in the project and the limited data, only linear lines were justified at this stage, noting however that at very low PPV these lines are likely to be not applicable.

The chart is considered to be a useful empirical representation of the performance of Mt Charlotte's ground support in dynamic conditions. While there is scatter in the data, the overall trends are identifiable and are as expected. 


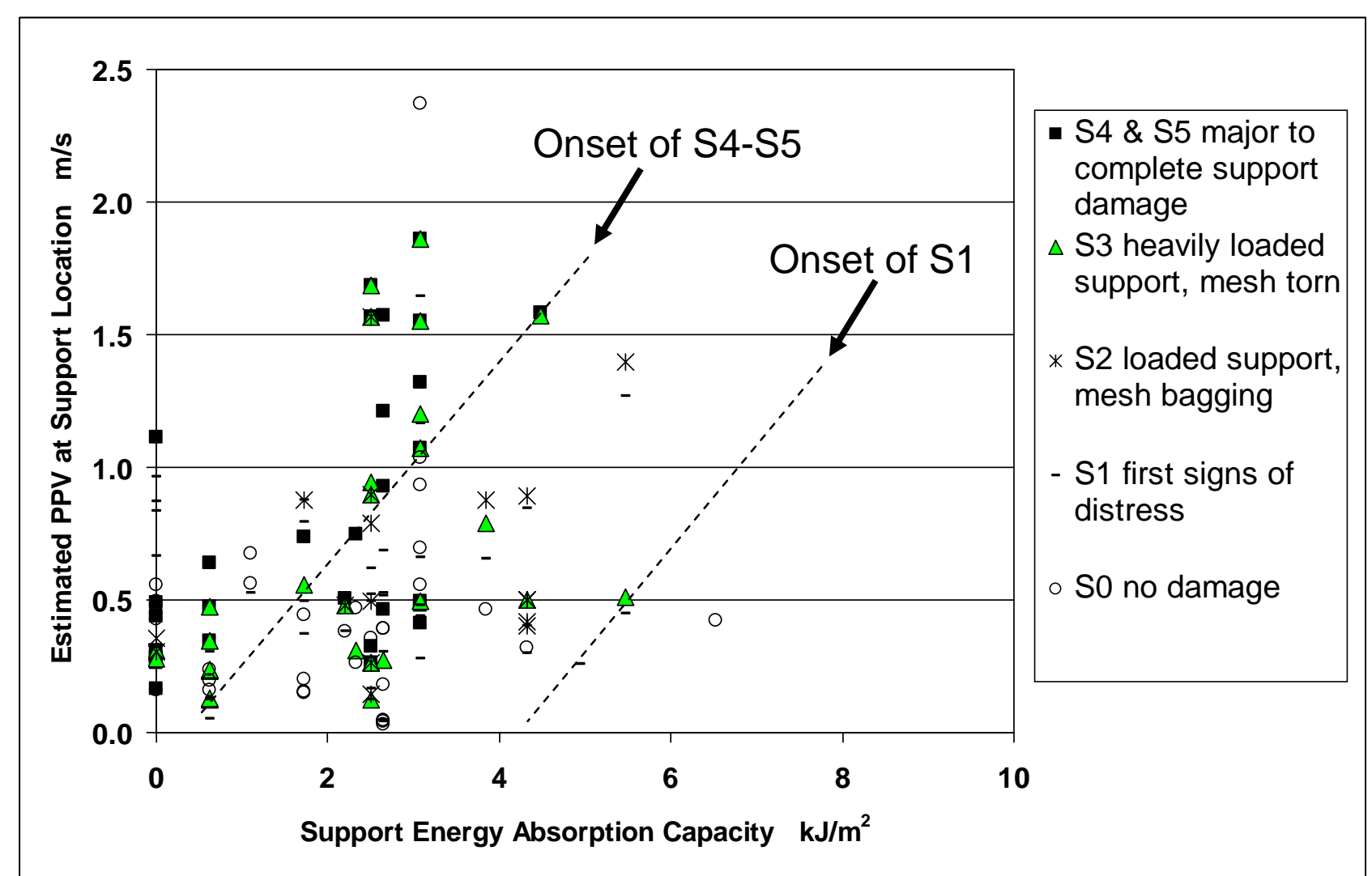

Figure 1 The relationship between PPV and ground support damage, using damage scales S0 to S5 as presented in Section 3

The chart shows that to avoid failure of ground support systems, their energy absorption capacity must increase if higher PPVs are anticipated. Note that the conclusions drawn from the chart do not materially change if the PPV or assumed energy absorption calculations are biased or inaccurate.

For an anticipated PPV and using the "Onset of S1" performance line in Figure 1, it is possible to determine the minimum required energy absorption capacity for an adequate ground support system. This is given in Equation 2 and Table 4:

$$
\mathrm{E}=2.6 \mathrm{PPV}+4.2
$$

Where

$\mathrm{E}=$ Minimum required energy absorption for adequate performance $\left(\mathrm{kJ} / \mathrm{m}^{2}\right)$

$\mathrm{PPV}=$ Estimated peak particle velocity $(\mathrm{m} / \mathrm{s})$

Conversely, it is possible to calculate PPVs and estimate the likely performance of ground support at various locations following a seismic event of a given magnitude.

Table 4 PPV vs minimum required energy absorption to avoid "Onset of S1" damage

\begin{tabular}{cc}
\hline PPV (m/sec) & Minimum required energy absorption $\mathbf{( k J / \mathbf { m } ^ { 2 } )}$ \\
\hline 0.5 & 5.5 \\
1.0 & 6.8 \\
1.5 & 8.1 \\
2.0 & 9.4 \\
\hline
\end{tabular}


The design procedure is:

- Estimate the likely level of seismic hazard, that is, the largest expected event magnitude that may affect the area under review. Mt Charlotte uses MS-RAP tools (Mine Seismicity Risk Analysis Program, ACG, 2007) to estimate this magnitude and event location.

- Use Equation 1 or Table 2 to estimate anticipated PPV per location in this area, for an assumed hypocentre of the anticipated largest seismic event.

- Use these PPVs and Equation 2 / Table 4 to determine the minimum required energy absorption capacity of the ground support system in the area under review.

- Use Table 3 and the mine’s available ground support elements to design support systems, for each location, that meet the minimum required energy absorption capacities.

Energy absorption capacity is just one of the support criteria that must be met. It is essential to also ensure adequate static load-bearing capacity to retain wedges and the broken rock mass after a seismic event, and to ensure adequate surface support capacity to retain broken rock between bolts.

The slope of the division lines in Figure 1 could also be interpreted to represent the "Support Multiplier" concept as a "Rule-of-Thumb" mentioned earlier. Thus for each extra $1 \mathrm{~m} / \mathrm{sec}$ of PPV, the support system needs to provide an extra $2.6 \mathrm{~kJ} / \mathrm{m}^{2}$ of energy absorption in order to avoid damage.

\section{Application of the dynamic ground support design chart}

The above design procedure was applied to the recent ROB5 remnant extraction at Mt Charlotte, for which the largest event was $M_{R}$ 2.2, occurring about $10 \mathrm{~m}$ from the excavations (Kempin et al., 2007).

- From Equation 1, this implies a PPV of $1.76 \mathrm{~m} / \mathrm{s}$ in the highest hazard sections of development.

- From Equation 2, this requires an energy absorption capacity of about $8.8 \mathrm{~kJ} / \mathrm{m}^{2}$ for zero damage.

- From Table 3, the installed ground support system (comprising mesh with a mixture of $50 \% 3 \mathrm{~m}$ split sets and $50 \% 2.4 \mathrm{~m}$ resin point anchored bolts, with cables on a 1 by $1 \mathrm{~m}$ pattern) has an energy absorption capacity of $8.3 \mathrm{~kJ} / \mathrm{m}^{2}$.

Figure 1 therefore implies that the ground support should have survived, but with some distress. This is in fact what happened generally - the installed ground support survived except for a localised upper wall failure.

\section{Conclusions}

Sufficient site-specific data has been collected at Mt Charlotte to allow the development of a design chart for ground support systems in development exposed to dynamic conditions. The approach uses information easily collected from underground observations or published in the literature. While the design chart in this paper is site-specific for Mt Charlotte, the same principles could be applied at other mines.

The design chart provides an estimate of the minimum dynamic support required, in terms of energy absorption capacity, for an adequate ground support system. It can also give an estimate of the likely performance of the ground support system, in terms of damage severity, for anticipated worst-case seismicity.

The chart has been successfully applied to assess dynamic ground support requirements in development used to mine remnants in the seismically active ROB5 stoping block.

As well as meeting energy absorption capacity criteria, for dynamic conditions, ground support designs must also ensure adequate bolt load capacity and surface support to retain broken rock after a seismic event.

Compilation of empirical design charts, such as that presented in this paper, relies on the systematic collection of appropriate data. Practitioners are encouraged to develop and use systems to facilitate data collection during underground observations. Good historical records are invaluable. 
Several avenues for further research include:

- Detailed industry-wide data collection of seismic damage experience.

- Study of frequency spectrum versus frequency response of mine development openings.

- The mechanics of reflection in massive versus blocky rocks.

- The methodology to estimate the energy versus momentum balance of supported exposures.

While the objective must always be the best possible understanding of complex situations, the development of simple empirical site-specific methodologies can be a useful, practical and sufficient alternative to the formulation of engineering designs from first principles.

\section{Acknowledgements}

The authors wish to express their appreciation to KCGM for permission to publish this paper.

\section{References}

ACG (2007) MS-RAP data. Australian Centre for Geomechanics internet site http://www.ms-rap.com.

Albrecht, J. and Sharrock, G. (2006) A model to forecast rockburst damage. ${ }^{\text {rd }}$ International Seminar on Deep and High Stress Mining Conference, Quebec, October.

Ansell, A. (2004) A finite element model for dynamic analysis of shotcrete on rock subjected to blast induced vibrations. Shotcrete: More Engineering Developments - Barnard (ed), Taylor and Francis, London, pp. 15-26.

Fraser, S.J., Mikula, P.A., Lee, M.F., Dickson, B.L. and Kinnersly, E. (2006) Data mining mining data - order vector quantisation and examples of its application to mine geotechnical data sets. $6^{\text {th }}$ International Geology Conference, Darwin, 22-23 August.

Heal, D. (2005) Ground support for rockbursting conditions. Section 8, Advanced Geomechanics - Theory and Practice. Course Number 0502w presented by Australian Centre for Geomechanics, Ibis Hotel, Perth, March.

Heal, D., Potvin, Y. and Hudyma, M. (2006) Evaluating rockburst damage potential in underground mining. $41^{\text {st }}$ U.S. Symposium on Rock Mechanics, Colorado, June.

Kaiser, P.K, McCreath, D.R. and Tannant, D.D. (1995). Rockburst Support Handbook, Geomechanics Research Centre, Laurentian University, Canada.

Kaiser, P.K., Tannant, D.D. and McCreath, D.R. (1996) Drift support in burst-prone ground. CIM Bulletin, Vol. 89, No. 998, pp. 131-138.

Kaiser, P.K., Tannant, D.D., McCreath, D.R. and Jesenak, P. (1992) Rockburst damage assessment procedure. Rock Support in Mining and Underground Construction, Kaiser and McCreath (eds), Balkema, Rotterdam, pp. 639-647.

Kempin, M., Sprague, A., Narendranathan, S., Mikula, P.A. and Lee, M.F. (2007) Destressing the ROB5 orebody using Tight Slot Blasting at Mt Charlotte Mine. $4^{\text {th }}$ International Seminar on Deep and High Stress Mining, Perth, November.

Li, T. (2002) Dynamic capable ground support rationale and system development. Presentation to the GCG (WA) Workshop on Dynamic Capable Ground Support, 12th November, 2002, Kalgoorlie.

Mikula, P.A. and Lee, M.F. (2000) Bulk low-grade mining at Mt Charlotte Mine. Proceedings MassMin 2000, Brisbane, pp 623-635.

Ortlepp, W.D. (1997) Rock Fracture and Rockbursts. Monograph M9, The South African Institute of Mining and Metallurgy, Johannesburg.

Wilson, J.A. and Lam, N.T.K. (2006) Recent developments in the research and practice of earthquake engineering in Australia. Australian Earthquake Engineering Conference, Canberra, 24-26 November. 